\title{
Revolución: la palabra, el acontecimiento, el hito fundador (Nueva Granada, 1780-1839)
}

Révolution: le mot, l'évènement, l'évènement fondateur (Nouvelle Grenade, 1780-1839)

Revolution: the word, the event, the landmark founder (New Granada, 1780-1839)

Isidro Vanegas

\section{OpenEdition}

Journals

Edición electrónica

URL: http://journals.openedition.org/bifea/2104

DOI: 10.4000/bifea.2104

ISSN: 2076-5827

Editor

Institut Français d'Études Andines

Edición impresa

Fecha de publicación: 1 abril 2010

Paginación: 85-104

ISSN: 0303-7495

\section{Referencia electrónica}

Isidro Vanegas, « Revolución: la palabra, el acontecimiento, el hito fundador (Nueva Granada,

1780-1839) », Bulletin de l'Institut français d'études andines [En línea], 39 (1) | 2010, Publicado el 01 octubre 2010, consultado el 06 noviembre 2020. URL : http://journals.openedition.org/bifea/2104 ; DOI : https://doi.org/10.4000/bifea.2104

\section{(@) $\odot \Theta$}

Les contenus du Bulletin de l'Institut français d'études andines sont mis à disposition selon les termes de la licence Creative Commons Attribution - Pas d'Utilisation Commerciale - Pas de Modification 4.0 International. 


\title{
Revolución: la palabra, el acontecimiento, el hito fundador (Nueva Granada, 1780-1839)
}

Isidro Vanegas*

\begin{abstract}
Resumen
Este texto hace un seguimiento al uso del término «revolución» en la Nueva Granada durante este periodo crucial. Pero no se trata de una simple reseña de los sucesivos significados que se le otorgaron, sino de acercarnos a través de él a la naturaleza de la sociedad monárquica y de la revolución que la deshace. Busca por lo tanto aprehender el orden que la revolución neogranadina confrontó y transformó de manera sustancial así como el lugar que los hombres públicos dieron a la mutación revolucionaria, y las esperanzas que en ella depositaron.
\end{abstract}

Palabras clave: «revolución», Nueva Granada, democracia, sociedad monárquica

\section{Révolution: le mot, l'évènement, l'évènement fondateur (Nouvelle Grenade, 1780-1839)}

\section{Résumé}

Cet article présente l'historique des usages du terme «révolution» en Nouvelle Grenade durant la période cruciale des années 1780-1839. II ne s'agit pas, cependant, de rendre compte de ses significations successives, mais de s'approcher, par le biais de ce terme, de la nature de la société monarchique et de celle de la révolution qui l'a détruite. Il s'agit également d' appréhender l'ordre auquel la révolution néogrenadine a fait face et qu'elle a transformé de manière substantielle, et de mesurer la place que les hommes publics ont accordé à la mutation révolutionnaire, et les espoirs qu'elle a créés chez eux.

Mots clés : «révolution», Nueva Granada, démocratie, société monarchique 
Revolution: the word, the event, the landmark founder (New Granada, 1780-1839)

\section{Abstract}

This article tracks the use of the term «revolution» in New Granada during the crucial period of 17801839. This is not a simple summary of the significant events that occured, but a closer analysis of the to grasp the order that the revolution in New Cranada confronted and changed substantially, as the place that public men a mutation that was revolutionary, and the hopes placed in it.

Key words: «revolution», Nueva Granada, democracy, monarchical society

A los hombres que vivieron la revolución neogranadina de la década de 1810 no se les escapó la notable alteración del lenguaje que se operó durante esos acontecimientos. La palabra misma «revolución» sufrió una mutación trascendental respecto al significado que los neogranadinos le habían otorgado dentro de la sociedad monárquica.

Tomando como parteaguas ese momento revolucionario, este artículo hace un seguimiento al uso del término «revolución» durante tres momentos. En primer lugar durante las décadas que precedieron a la crisis monárquica, cuando el horror de los neogranadinos a la mutación revolucionaria nos pone en contacto con la solidez del orden monárquico. En segundo lugar durante el periodo revolucionario (1808-1816), donde indago cómo la noción de «revolución» es aprehendida en la revolución misma, cómo el acontecimiento revolucionario se designa a sí mismo y cómo esa designación revela ciertos temores y expectativas, buscando además asir el curso de la revolución a través de la manera como los contemporáneos la nombran. En tercer lugar, durante el periodo 1816-1839, poniendo especial atención al lugar que le fue asignado al acontecimiento revolucionario en el relato fundacional de la nación. Entre la exigencia de terminar o continuar la revolución, la persistencia de la cuestión revolucionaria en el lenguaje de las luchas políticas durante este periodo que denomino la república de los héroes, nos pone en contacto con la inevitable división de la sociedad democrática engendrada al momento de la ruptura con la monarquía hispánica. En uno u otro momento, no se trata simplemente de describir la manera como el término «revolución» fue utilizado, de mostrar sus significados, sino de acercarnos a través de ese ejercicio a la naturaleza de la mutación revolucionaria, y de la sociedad que esa revolución enfrentó y transformó de manera sustancial.

\section{LA REVOLUCIÓN: UN «DELIRIO CRIMINAL»1}

Observando ligeramente los escritos y las actitudes de algunos revolucionarios de la década de 1810, es forzoso percibir cómo ellos fueron, hasta el advenimiento

1 Un desarrollo pormenorizado de lo planteado en este apartado puede verse en Vanegas (2009). de la revolución, unos fieles vasallos del monarca español, que si bien pudieron conocer la literatura revolucionaria e incluso simpatizar con la República, sin embargo durante el periodo monárquico no se pensaron en absoluto como agentes de un cambio revolucionario. José María Salazar escribió en 1804 un poema de ardiente patriotismo para celebrar la llegada a Santafé del virrey Amar y Borbón. Andrés Rosillo en un sermón de 1805 manifestó que el gobierno de la monarquía española era el mejor que pudiera apetecer el hombre. En el Semanario del Nuevo Reino de Granada no solo fue vindicado en 1808 el rey como padre de su pueblo sino que fueron proyectadas unas escuelas patrióticas en las que los niños le deberían rendir homenaje. José Acevedo y Gómez, ese mismo año, redactó un regocijado informe de las festividades celebradas por Santafé para reconocerse como fieles súbditos de Fernando VII. Antonio Nariño, como nos lo cuenta el cura José Antonio Torres y Peña, se ofreció en 1808 al Virrey para hacer la jura de Fernando VII ante la falta de Alférez Real en Santafé. José Fernández Madrid deploró en 1809 la cautividad de ese soberano a quien describe como el «astro deseado» que da vida a la nación2.

Aunque la pregunta sea en sí misma problemática, podríamos preguntarnos por qué, antes del acontecimiento revolucionario de la década de 1810, estos hombres no tuvieron como horizonte la revolución. ¿Por qué sucedió eso si ellos fueron en la década de 1810 adalides de los cambios revolucionarios y muchos de ellos sacrificaron su vida en esa tentativa? Para responder a esa cuestión resulta útil indagar acerca del significado del término «revolución» en la sociedad en la que ellos se formaron.

Es bien sabido que la palabra «revolución» sirvió en la segunda mitad del siglo XVIII para aludir a fenómenos celestes, como nos lo informa por lo demás el diccionario de Esteban Terreros (1788), quien nos revela que dicho término es usado por astrónomos o astrólogos para aludir al ciclo de los planetas o de los hombres. Terreros nos revela igualmente que «revolución se dice también de las mudanzas, y variedades extraordinarias que suceden en el mundo, como desgracias, infelicidades, decadencias, \&c.» Por último, agrega que esa palabra es asociada a «tumulto, desobediencia, sedición, rebelión», «mutación, variedad, vicisitud» (Terreros y Pando, 1788).

Entre esa variedad de significados me concentraré en tratar de entender qué designa el término «revolución» en su sentido «político», y de qué ordenamiento social participa esa noción en medio de las novedades en el gobierno y las costumbres alentadas a finales del siglo XVIII por la misma Corona. Me sirvo fundamentalmente de tres fuentes: la primera, El vasallo instruido en el estado del Nuevo Reino de Granada y en sus respectivas obligaciones, un escrito de la década

2 José María Salazar en el poema, «El placer público de Santafé», celebra el arribo del «Excelentísimo Senor don Antonio Amar y Borbon, Caballero profeso del orden de Santiago, Teniente General de los Reales Exércitos, Virrey, Gobernador y Capitán General del Nuevo Reyno de Granada, y de la Excelentísima Señora su Esposa Doña Francisca Villanova y Marco» (1804); Andrés María Rosillo (1805); «Discurso sobre la educación» (1808); José de Acevedo y Gómez (1808); José Antonio Torres y Peña (1960: 82); José Luis Fernández de Madrid (1809). 
de 1780 (no publicado) del sacerdote Joaquín de Finestrad (2000). La segunda, el Papel Periódico de Santafé de Bogotá (1978), del cual fueron publicados 265 números entre 1791 y 1797. La tercera, el proceso seguido contra Antonio Nariño (Hérnandez de Alba, 1984), entre 1794 y 1811.

Este acervo documental revela cómo, durante el tiempo en que reinan Carlos III y Carlos IV, la palabra «revolución» no porta esperanzas sino temores: es asociada a sedición, rebelión, conjuración, conmoción, sublevación, revuelta, levantamiento, insurrección; todos denotan una inmoral alteración del orden en esa sociedad que hemos definido como «sociedad monárquica» y no como «sociedad colonial», dislate este que hace evidente un sencillo ejercicio de historia conceptual.

Las revoluciones políticas son para los súbditos neogranadinos algo abominable, son una perspectiva que les produce un gran temor en la medida que, al final, solo ven la violencia y la desintegración de la sociedad. Este sentido aciago del término «revolución» lo vemos expresado claramente en un acontecimiento muy importante de este periodo: la revuelta de los comuneros de 1781 iniciada en la provincia del Socorro. Revisando la amplia documentación compilada por Juan Friede encontramos que apenas en una ocasión alguien de la época describe esa movilización antifiscal como la «revolución de los comunes», siendo utilizado el término de manera generalizada para aludir más bien a la confusión y los estragos de las protestas 3

El cura Finestrad, uno de los encargados de pacificar dicha provincia, describe esa protesta como «aquellos infelices tiempos de revolución y trastorno en que el espíritu de tinieblas se difundió por todos esos lugares». Y consagra todo $E$ I vasallo instruido a mostrar que los súbditos no tienen derecho a rebelarse contra su príncipe ni siquiera en la eventualidad de que este sea un déspota. El desacato a las autoridades legítimas es un acto pecaminoso, dice Finestrad, y solo a Dios le está reservado el derecho de castigar el despotismo o los abusos del monarca. Para él «revolución» no solo es un desquiciamiento del natural sosiego y quietud de los vasallos sino una injustificable alteración del buen orden que rige la sociedad, orden que tiene su fundamento en la figura del monarca (de Finestrad, 2000: $367-371 ; 374-375)$

Manuel del Socorro Rodríguez, el editor del Papel Periódico de Santafé (1978), por su parte, utilizó el término «revolución» especialmente a la luz de la revolución francesa, de la que se ocupó con asiduidad en su periódico. Para Manuel del Socorro la revolución introduce en la sociedad una violencia que llega hasta la destrucción mutua de los revolucionarios. Piensa igualmente que la revolución conlleva una inversión del orden legítimo en cuanto instaura una pretensión igualitaria que quiebra la idea jerárquica que ordena la sociedad. Un igualitarismo

3 En las capitulaciones redactadas por Berbeo no se deja de reconocer la sujeción al monarca y el egítimo derecho a cobrar tributos. En otros apartes manifiesta que en el Reino del Perú «debieran haber cesado en su revolución pues ningún monarca puede sostenerse sin algunas contribuciones de sus vasallos» (Friede, 1982; las alusiones a «revolución» en t. 1: 12, 76, 98, 144, 166, 335, 337, $356,370,385 ;$ t. $2: 584,712,747,752,759,889,1036,1043$. antinatural a sus ojos, y que rompe con los criterios tradicionales para definir lo que es precioso y útil, para definir quién manda y quién obedece. La revolución, piensa Manuel de Socorro, hace que nadie sepa cuál es el lugar que le corresponde en la sociedad, y que todo se torne precario y volátil. Las extravagancias de la revolución francesa se resumen, según él, en la pretensión de erigir una república en lugar de la monarquía, en la pretensión, en últimas, de instituir el «quimérico sistema de la igualdad»s.

El caso de Antonio Nariño, tenido por precursor de la revolución neogranadina, es más importante aún de ser observado. Nariño fue encarcelado en 1794 por traducir e imprimir los derechos del hombre y acusado también de trabajar por un levantamiento del Reino, para, según sus propias palabras, instaurar «el sistema fanático de los franceses», una acusación que Nariño rechaza como un «delirio tan criminal, que no cabe en su pensamiento». Después de una brillante defensa que en realidad sirvió para ahondar los temores de las autoridades virreinales, Nariño fue enviado preso y en el trayecto escapó, pasando a Francia e Inglaterra donde realizó algunas gestiones en busca de apoyo para la separación del Nuevo Reino respecto a la metrópoli. Nariño regresó al Nuevo Reino y trató de sublevar algunos pueblos, pero intempestivamente se entregó a las autoridades, al no encontrar ningún apoyo para sus planes de rebelión, de los cuales ni siquiera había enterado a su familia. Ante las autoridades Nariño delató minuciosamente a todos los que lo ayudaron, a los escasísimos que simpatizaron con sus ideas y a los que simplemente lo escucharon, muchos de ellos individuos que si no fuera por su confesión nadie hubiera podido conocer. Y lo que es más importante: Nariño delató hasta sus mismos pensamientos. Su confesión está marcada por expresiones como «Asaltóme el terrible pensamiento», «el pensamiento era demasiado desesperado», «he dicho cuanto he hecho y cuanto he pensado». Nariño redactó posteriormente un proyecto de reformas para el mejor gobierno del Reino, $y$, como he indicado, se ofreció en 1808 para hacer la jura de Fernando VII en Santafé (Hernández de Alba, 1984, t. 1: 294; t. 2: 72, 109, 159-180).

En la tentativa de rebelión de Nariño de los años 1794-1797 es posible observar una especie de profunda turbación de la voluntad ante la enormidad de la pretensión: el desafío a un orden natural, a un buen orden en el que los principios católicos y el monarca aparecen como referentes establecidos desde siempre para dar a los «inferiores» la felicidad en la obediencia. Lo angustioso de esa tentativa de Nariño de rebelar el Reino permite observar cómo el poder monárquico aparece a los ojos de sus súbditos con los atributos de algo eminente, misterioso e inmemorial, lo cual convierte en monstruosa la idea de que ese poder pueda ser impugnado, pues tal acto supone ignorar la razón, ofender las enseñanzas de la religión, transgredir la tradición. De la naturaleza del poder del monarca nos hablará Simón Bolívar mucho después, cuando aluda a la monarquía como un gobierno «cuyo origen se pierde en la oscuridad de los tiempos», lo cual significa, dice el caraqueño, 
que ese gobierno ofrece barreras muy fuertes a quienes pretenden sustituirlo (EI Mensajero..., 1814).

Que en la sociedad monárquica de la segunda mitad del siglo XVIII y primera década del XIX el término «revolución» no haya sido asociado sino a atributos nefastos permite comprender que el evento revolucionario de la década de 1810 en la Nueva Granada, y tal vez en la América hispánica, haya sido una «revolución» sin precursores5. De esto no hay que extrañarse: en las revoluciones de aquel periodo, entre ellas la revolución francesa, sucedió algo similar6. La existencia de revolucionarios consagrados a hacer una revolución es posterior a este tipo de revoluciones, y propio más bien de sucesos como la revolución bolchevique.

\section{2. «LA FELIZ CATÁSTROFE»}

En contraste con el periodo anterior a la revolución, durante «el momento fernandino», esto es, durante el periodo en que con gran emotividad es ratificada la lealtad a la monarquía — periodo que en el Nuevo Reino va de mediados de 1808 a mediados de 1809-, vemos emerger en medio de los sucesos desgraciados de la monarquía hispánica un significado positivo para la palabra «revolución».

Ese sentido venturoso de la palabra «revolución» nace en medio del alud de anatemas que vemos arrojar sobre la revolución francesa y sobre el producto de ella: Napoleón Bonaparte, el captor de la familia real y el agresor de la nación española, de quien escribieron en un periódico que «Solo la revolución de la desdichada Francia pudo abortar un malvado» como ese. Porque si la revolución francesa y Bonaparte designan toda una serie de temores (violencia, irreligiosidad, libertinaje) la vigorosa resistencia que se ve aparecer en la península a la agresión de los franceses es pensada como una serie de acontecimientos que portan la marca del designio divino, y llega incluso a ser definida como una «revolución feliz» a la manera de la que Dios había anunciado a los judíos. Se trata de un acontecimiento afortunado, dicen, no solo porque permite a los españoles reafirmar su fe católica sino porque, como escribieron a comienzos de 1809, «la Monarquía Española está en el día presentando en todos ramos la época más prodigiosa que han visto los siglos». Se dice que sin quererlo, la agresión napoleónica ha permitido a la nación española salir de su letargo y mostrar todo su vigor (Redactor Americano..., 1808; de Torres y Peña, 1809: 13; El Alternativo del..., 1809).

El enriquecimiento del término «revolución» con la adición del significado de sacudimiento venturoso expresa - hay que recalcarlo- un viraje fundamental. La tensa dupla de sentidos que porta ahora el término «revolución» la muestra bien una frase del abogado cartagenero José María Castillo y Rada a mediados de

5 Precursor: «Se aplica a lo que anuncia o inicia algo que tiene su completo desarrollo posteriormente» (diccionario de María Moliner).

6 Un trabajo específico sobre la cuestión en Timothy Tackett (1997).

Las formulaciones hechas en este apartado se desprenden de la revisión de una base de datos que reúne 16 mil páginas de documentos fechados entre 1808 y 1816 y que, en su inmensa mayoría, fueron elaborados por neogranadinos.
1809, cuando afirma que «la presente revolución, tan funesta por una parte como gloriosa por otra, ha producido efectos asombrosos» (Monsalve, 1920, t. I: 292).

Hay que recalcar además que los atributos inéditos que ahora pueden ser asignados al término «revolución»son una muestra de la sincronía existente entre América y la península en la manera de entender la resistencia a Napoleón y todo lo que de ello se deriva. Revolución no solo no es ya algo simplemente execrable: es por el contrario, una dinámica que las mismas autoridades supremas se encargan de alentar. Esa «revolución española», como se la designa, con la que se creen en camino de recuperar la libertad y restaurar el orden social, parece una revolución de un género distinto a todas sus antecesoras, liberada de unos desbordamientos familiares a los Antiguos y a los Modernos. Así, la Junta Suprema puede creer - lo dice en octubre de 1808- que la «revolución española» tendrá un carácter enteramente opuesto a la revolución francesa. Mientras que a esta la asocian a violencia, desunión, intrigas, choque de opiniones, a la revolución española le otorgan el carácter de algo unánime, armonioso e incruento. En la revolución española, afirman, «no hay más que una opinión, un voto general: Monarquía hereditaria, y Fernando Séptimo Rey». De esta manera la Junta Suprema pretende enunciar el único sentido posible para la «revolución española»; pretende dotar a esta revolución de un sentido compartido por la universalidad de los españoles de ambos hemisferios. Pero la Junta no se limita a postular como objetivos el rechazo de la agresión francesa y el retorno de la monarquía a su curso normal: la Junta se hace altavoz de un ideal de cambio: cree que los españoles sabrán «sin trastornar el Estado, mejorar sus instituciones y consolidar su libertad»: da impulso así a la idea de que la revolución es un objetivo que debe proseguir su curso al interior de la sociedad y ahonda de esta manera las incertidumbres en una situación de por sí plagada de incertidumbres (Gaceta de Caracas, 1809a).

Exaltando la revolución se lanza la sociedad por un camino de grandes riesgos que parecen permanecer ocultos bajo las enormes ilusiones que las autoridades de la península provocan o profundizan. La Junta Central se hace adalid del ideal de «regenerar la monarquía», un ideal que quizá flota en el ambiente pero que bien puede ser considerado como una de las ideas más disolventes que pudieron abanderar las autoridades peninsulares. Nombrar el acontecimiento que están viviendo como «revolución española» es de por sí decisivo. Al dar un estatus oficial a esa designación le quitan el carácter faccioso que pudiera haber tenido y convierten la revolución en un objetivo cuyos alcances esa frágil autoridad no puede en absoluto controlar. Como partícipes tan intensos de los eventos de la nación española que se desarrollan en la península, los neogranadinos se apropian de esa ilusión de regeneración: lo podemos ver, entre otros documentos, en una conocida representación que algunos regidores del Cabildo de Santafé redactan a finales de 1809 en la que aluden al «día tan deseado de esta regeneración feliz, que ya nos anuncia V. M.» la Junta Central (Gaceta de Caracas, 1809b; Hernández de Alba, 1960: 93)8.

${ }^{8}$ La apropiación en América del ideal de regeneración lo vemos en un texto limeño reproducido en Santafé en el que exclaman: «iQué idea tan lisonjera para sus colonias la regeneración de la 
Pese a participar de este ideal de regeneración de la monarquía, los neogranadinos poco recurren a la palabra «revolución» durante este periodo de afirmación lealista sirviéndose de esa expresión sobre todo para execrar la junta de Quito en agosto de 18099.Los acontecimientos de Quito, sin embargo, contribuyen a radicalizar los cuestionamientos al poder monárquico que diversos notables neogranadinos habían comenzado a manifestar meses antes, particularmente bajo la forma de una sospecha sobre la capacidad y el interés de las autoridades virreinales para proteger el Reino de la amenaza francesa. En esta actitud no hay solo temores sino esperanzas nuevas que un tiempo tan incierto ha incrementado a gran velocidad, como lo vemos en las juntas erigidas por doquier a mediados de 1810.

Con la creación de esas juntas se asiste a una agudización de la ambigüedad frente al poder monárquico, pues si por un lado las juntas se designan a sí mismas como defensoras de los derechos de Fernando VII, ellas deponen a las autoridades en la mayor parte del Nuevo Reino. De esta manera la sociedad neogranadina se ve lanzada a un torbellino.

Del dramatismo del acontecimiento es testimonio no solo la súbita proliferación del término «revolución» sino la sublimación que se hace de ella: «revolución la más activa, misteriosa y feliz que se vio jamás», «maravillosa revolución», «revolución santa», «feliz revolución», «feliz catástrofe», son algunas de las maneras de nombrarla (La Constitución Feliz, 1810, t. 1: f. 599v; Diario Político de Santafé de Bogota, 1810; AGN, Fondo Justicia, t. 9: f. 143).

Bien es cierto que esta manera ditirámbica de designar la creación de la junta y sus resultados no es algo uniforme en todo el Reino, pues en ciudades como Cartagena son cautos para hablar del acto de deposición del Gobernador, prefiriendo expresiones como «regeneración de esta provincia», pero en Santafé y otros lugares la palabra «revolución» no solo es recurrentemente asociada a un acontecimiento feliz, sino que se tiene conciencia de que algo extraordinario está sucediendo. José Gregorio Gutiérrez, por ejemplo, le escribe a su hermano seis días después de instalada la Junta de Santafé diciéndole:

«estoy atolondrado, y todavía me parecen sueños. Los sucesos son tan memorables, que no han tenido ni tendrán iguales en la América»10.

España!», al igual que en una carta de Camilo Torres en la que este habla de los diputados a Cortes como los hombres que harán la felicidad de la nación española «y a quienes deberá su existencia futura y su regeneración». Véase «Lima 17 de Diciembre de 1808. El amigo de la razón y de la verdad en Lima» en Redactor Americano... (1809); «Cartas de Camilo Torres» en Repertorio Colombiano (1989: 83)

Joaquín Caicedo, por ejemplo, le escribe a Santiago Arroyo el 14 de noviembre de 1809 felicitándose del lealismo de su hermano y de su tío, el obispo de Quito, durante la «revolución más espantosa ocurrida en aquella ciudad. Menos de un año después, Caicedo estará entre los principales líderes de la junta de Cali y escribirá con entusiasmo de los acontecimientos del mes de julio en la capita del Reino: «la revolución de Santafé hará época en la historia», dice. Véase «Para la historia. Documentos inéditos» en Popayán (1909a: 287) y «Para la historia. Documentos inéditos» también citado en Popayán (1909b, n.o XIX: 296 .

10 Ver el Informe del Real Consulado de Cartagena de Indias a la Suprema Junta provincial de la misma del 11 de cctubre de 1810 en Elias Ortiz (1965: 268, 270). El apunte de José Gregorio en Casa Museo Veinte de Julio (CMVJ), t. 3223, f. 38 .
La revolución es percibida como un acto providencial en la medida que, a diferencia de otras revoluciones, no ha significado ninguna efusión de sangre. La Junta de Santafé escribe, por ejemplo:

«No es esta una revolución premeditada, no es un tumulto popular en que el desorden precede a los estragos y a la carnicería: es un movimiento simultáneo pero pacífico de todos los Ciudadanos» (Archivo Histórico José Manuel Restrepo, 1810, vol. 8, fondo 1: f. 6v).

Esa revolución incruenta y unánime es para los líderes revolucionarios un acontecimiento de consecuencias graves no solo porque significa, como dicen, una «entera transmutación» del gobierno sino también porque el campo en el que ven desarrollarse los acontecimientos es la América toda. Pero esta percepción es simultánea con su calificación de la revolución como algo inesperado e impreparado, una formulación que es el lógico corolario de sentir que la generosidad y la lealtad de los neogranadinos hacia Fernando VII, así como su adhesión a la nación española, han sido correspondidos por las autoridades peninsulares con el desdén o la ingratitud (Posada, 1914: 189; 319; La Constitución Feliz, 1810; Gutiérrez \& Martínez, 2008: 68). En los primeros meses del brote juntista la revolución entonces es pensada como una respuesta al despotismo y la ignorancia secularmente irradiadas desde España, al igual que como una salida a lo que califican como actos arbitrarios de las autoridades virreinales. La revolución significa tanto la restauración de una libertad o de unos derechos perdidos como el escarmiento de unos funcionarios juzgados hostiles a los americanos.

Pero si en el momento que sigue a la instalación de las juntas provinciales el término «revolución» remite casi exclusivamente a esperanzas, no tarda en producirse una diversificación de los sentimientos y las maneras de dar cuenta de la revolución. No se trata en absoluto, sin embargo, de que surjan grupos relevantes que nieguen la justeza del movimiento, pues vemos incluso generalizarse la idea según la cual la revolución es el resultado del despotismo de los españoles en el sentido que a estos se les asigna un carácter intrínsecamente perverso, desapareciendo prácticamente la arbitrariedad virreinal de las explicaciones del cambio de gobierno11. La revolución aparece como algo fatal aun cuando vemos también insistir en el «trastorno general que acompaña las convulsiones políticas», o en «los trastornos inevitables de la revolución». La revolución, advierten algunos, trae necesariamente aparejados ciertos males que hay que tratar de limitar, pero que para otros simplemente hacen estéril la mutación. Un cierto escepticismo respecto a la revolución —-más perceptible en ciertos individuos y en ciertos momentos-

11 Una muestra de la manera de pensar respecto a los españoles: «iLa España agotada, moribunda (parece increíble tanta insensatez), la España que si acaso existe todavía es solo por el estímulo irritante de su orgullo, la España ocupada por el francés aun pretende esclavizar al nuevo mundo! [...] Habitantes del nuevo Continente, generosos hijos de Colón! cuando tenemos la felicidad en nuestras propias manos, es un delirio, una quimera esperarla de nuestros tiranos, de nuestros enemigos naturales» (EI Argos Americano, 1811). 
acompaña esa advertencia de los males que ven venir con ella (Gazeta Ministerial de la República de Antioquia, 1815; El Republicano, 1815)12.

Uno de esos males es el de los fomentadores de revoluciones, de los promotores de algún tipo de alteración del orden o desafío a la autoridad. Revolución, en este sentido retoma un significado antiguo que revela una fuerte ansia de concordia y de unidad del cuerpo social. No se trata aquí de la existencia de un tipo de agitadores unánimemente repudiados sino de la necesaria división de la nueva sociedad, lo cual permite que unos y otros puedan utilizar el calificativo de «revolucionario» como anatema para indicar una intención malintencionada de impedir la consolidación de la autoridad, acusación que puede ir hasta convertir a los acusados en contrarrevolucionarios. Más específicamente, encontramos aquí dos reclamos. Uno contra quienes se acusan de buscar simplemente meter desorden, contra los alborotadores («revolucionar» es el verbo que indica esta acusación). Otro contra aquellos a quienes se acusa de pretender cambiarlo todo - al respecto se alude a «la manía de innovarlo todo» (Gazeta Ministerial de Cundinamarca, 1812; Nariño, 1812; La Bagatela, 1811; 1812; Gazeta Ministerial de la República de Antioquia, 1815)—.

Otro mal que asocian a la revolución es el de los intrigantes que se aprovechan de las novedades para abrir campo a su ambición, y el de los inescrupulosos que utilizan las novedades para saciar venganzas. Violencia, egoísmo, desunión del Reino, proliferación y choque de opiniones, los males acarreados por la revolución parecen resumirse en la lucha entre provincias, que en la Nueva Granada es tan acusada y tan temprana. Es por eso que el cartagenero José Fernández Madrid llama a cesar esas disensiones que desacreditan la revolución cuando advierte que la:

«masa general del pueblo, que siempre juzga por los hechos, comparando este desorden y choques con la antigua calma sepulcral en que yacía, forma el peor concepto de los autores y jefes de nuestra santa revolución, y cree que los sacrificios que se le exigen, no tienen otro fin que satisface a los caprichos, y particulares intereses de algunos pocos» (La Aurora de Popayán, 1814).

Los males de la revolución son fuertemente asociados al predominio de las pasiones, pudiendo pensarse que estas constituyen la más socorrida explicación de las derivas de la revolución. Multitud de expresiones nos hablan de ese desborde de las pasiones. Un cura dice en 1812: «nuestra revolución no podía ser

${ }^{12}$ José Gregorio Gutiérrez le dice a su hermano Agustín en agosto 19 de 1811: «Mi Padre me manda te diga en este correo que no le agrada nada tu comisión, lo primero porque es bastante arriesgada a pesar de lo que tú digas, y lo segundo porque dirigiéndose a trastornar las cosas, aunque sea una causa justa, las consecuencias, y resultados siempre son imputables a los autores de una revolución de cuyo bueno, o mal manejo pende una responsabilidad, a que es muy difícil satisfacer después. Yo soy del mismo dictamen, y aunque conozco la justicia de nuestra causa, y que era ya tiempo de sacudirnos, y echar a pasear a nuestros antiguos amos, no por eso dejo de conocer también que en nuestra revolución ha influido más el espíritu de venganza que el deseo puro de nuestra libertad, y felicidad» (CMVJ, t. 3223: f. 111). obra de hombres, sino de la furia infernal de todas las pasiones». Simón Bolívar habla «de turbulencia, de choque y de divergencia de opiniones» en medio de las cuales «el torrente de las pasiones humanas [...] agitadas por el movimiento de las revoluciones se aumentan en razón de la fuerza que las resiste». Una proclama del gobierno de la Unión indica que en «medio del fuego y trastornos de una revolución política las pasiones suelen adquirir tal grado de vehemencia y actividad que, o producen los hechos más sublimes y heroicos, o degeneran en el desenfreno y licencia más espantosa». Mientras que un individuo advierte del «precipicio a que os conducían los delirios políticos de la fiebre inevitable de una revolución», y otro más alude al «desenfreno de las pasiones que ha causado la revolución» (de Mendoza Bueno, 1814: 8; El Mensajero de Cartagena de Indias, 1814; Argos de la Nueva Granada, 1815; El Republicano, 1815; 1816).

La insistencia en asociar la revolución a una hipertrofia de las pasiones va de la mano con el establecimiento desde mediados de 1810 de un vínculo entre la revolución y el desencadenamiento de un gran entusiasmo, de una activación sin precedentes de la velocidad de los sucesos. Alguien habla del «tiempo de revolución, en que casi se han borrado los caminos por donde se debe marchar, y en que se precipitan los sucesos con tanta velocidad, que apenas dan lugar a la reflexión». La revolución es un tiempo en el que nadie ha podido permanecer al margen de los acontecimientos incluso contra los deseos propios. La revolución es además un tiempo de una aguda tensión nerviosa que recorre toda la sociedad, por lo que un periódico alude a «unas revoluciones tempestuosas, en que todos miden sus operaciones con la ansiedad» (Argos de la Nueva Granada, 1815; Década Miscelánea de Cartagena, 1814).

Por diversas razones esa febril revolución ve sin embargo decrecer el entusiasmo hacia las novedades introducidas luego de la expulsión de las autoridades virreinales. El Gobierno de Cartagena, por ejemplo, admite a mediados de 1814 que «la opinión de nuestros pueblos, nunca bien decidida por la naturaleza de los principios y motivos que obraron nuestra revolución, ha ido debilitándose por los sufrimientos, privaciones y sacrificios que necesariamente les ha impuesto, y las ningunas ventajas que de presente ha podido proporcionarles el nuevo orden de cosas». Mientras que Bolívar escribe en 1815 pronosticando que las provincias americanas terminarán emancipándose pero que «algunas serán tan infelices que devorarán sus elementos ya en la actual, ya en las futuras revoluciones». Se trata de un pronóstico que no pocos hacen sobre la inestabilidad y los desórdenes permanentes que le esperan a la América independiente (Posada, 1989, t. II: 5; Bolívar: 61)

Pero de manera simultánea con ese declive del entusiasmo se produce una radicalización de la revolución, que se expresa en el énfasis con que se reclama el tratamiento de «ciudadano», en la liberalidad hacia los esclavos, en la exaltación del papel de la mujer en las revoluciones políticas, en la vindicación de los agitadores, en la creación de tribunales de salud pública por doquier, y finalmente en la naturalización de la otredad respecto a los españoles, rasgo este que constituye la emergencia propiamente dicha de una diferenciación definitiva respecto a la 
madre patria (Gazeta Ministerial de Cundinamarca, 1815; Gazeta Ministerial de la República de Antioquia, 1814a; b; «A los Enemigos de la Esclavitud. Carta a reimpresor de la Bagatela num. 23», 1814: 2; «Voto del C. Dr. José Ignacio Losada sobre la expulsión de españoles europeos en la sesión, que el Serenísimo Colegio Electoral tuvo en Santafé el día 31 de Mayo de 1815», 1815).

Esa separación radical respecto a la nación española que introdujo la revolución no es contradicha por la valorización de la revolución española que vemos producirse luego del retorno de Fernando VII al trono. Si después de las juntas de 1810 se había dicho de muchas maneras que esa revolución española no había aportado sino decepciones, ahora se le apuntan algunas virtudes como haber vivificado el espíritu público o haber promulgado una constitución más o menos liberal. De manera que cuando Fernando VII acusa a los revolucionarios españoles de haber copiado «los principios revolucionarios de la Constitución francesa de 1791», en un periódico replican que el error de los españoles no radicó en haber realizado tal copia sino en haber desaprovechado la oportunidad de fijar tales principios. Esta valorización de la revolución española muestra cuánto debe la actitud separatista respecto a la metrópoli a una elaboración intelectual, esto es, que ella no consiste simplemente en la constatación de unos abusos seculares y de una otredad previa a la revolución. Pero esta valorización de la revolución peninsular es la oportunidad para indicar que esas venturosas novedades — entre ellas, las Cortes — son las que viene a derribar el Deseado, por lo que la revolución debe proseguir en América. El ocaso de la revolución española sirve pues, para renovar la separación respecto a la península (Argos de la Nueva Granda, 1815c).

Para los monarquistas neogranadinos, por el contrario, el retorno de Fernando VI representa simplemente el fin de una «espantosa y fatal revolución». El cura José Antonio Torres y Peña, uno de los escasos neogranadinos que dejó testimonio de su monarquismo, explica la revolución por la actividad de perversos intrigantes que valiéndose de la situación apurada que había vivido España con la crisis monárquica habían usurpado el lugar de las autoridades legítimas. Se trata, dice Torres y Peña, de una serie de «revolucionarios» con habilidad para manejar los hilos de la trama novadora (por eso habla de «secuaces del sistema revolucionario», «autores de la revolución», «fraude de los revolucionarios», «directores de la revolución», «designios revolucionarios», etc.). Novadores que encontraron su camino expedito porque la mayoría de vasallos fieles creyeron ingenuamente en sus buenas intenciones de defender la monarquía y el orden amenazados por los franceses (Torres y Peña, 1960: 83, 84, 85, 104).

Según Torres y Peña esos revolucionarios que buscaron hacer «un remedo de la revolución francesa» en el Nuevo Reino son básicamente unos enemigos del orden social. Para él la revolución significa automáticamente la licencia y la apertura a la irreligiosidad, siendo el principal designio de los revolucionarios establecer «una total independencia» y «una bárbara y absoluta libertad». Desde esta perspectiva los desastres producidos por la revolución son la confirmación del carácter aciago que es consustancial a la república o democracia con que se ha buscado sustituir el gobierno monárquico, como lo manifiesta otro cura para quien: «una Poliarquía es como un volcán que siempre vomita fuegos, y estragos, y que jamás reposa aunque pasen los siglos, que es una continua insurrección del Pueblo, que en ella el mérito es más peligroso que el delito; que la violencia, y la intriga ocupan el lugar de la Justicia; que ella es el Domicilio de la ingratitud, y el capricho; el teatro de las mudanzas, y catástrofes, la palestra de los celos, y la envidia, el lugar enemigo de la seguridad,

y fortuna, la Patria de la revolución, y una disposición perpetua para la más cruel tiranía» (Torres y Peña, 1960: 73, 67; de Valenzuela y Moya, 1817: 22).

Para los monarquistas, por lo tanto, es preciso borrar completamente la revolución, es necesario trazar un paréntesis sobre estos años. Dentro de este estado de ánimo el cura Antonio de León concluye en 1816 un sermón pronunciando unas palabras que desea ver suscritas por todos los neogranadinos:

«Oh Señor, si pecáremos en adelante, castigadnos primero con todos los

rayos de vuestra Divina Justicia, antes que con otra revolución» (de León, 1816: 50).

Sin embargo, un grupo importante de neogranadinos exiliados en las llanuras del Oriente y otros que esperaron la reconquista en sus hogares, están lejos de suscribir los deseos de este cura.

\section{3. «LA REVOLUCIÓN MÁS ATROZ Y MÁS BENÉFICA}

Luego que las fuerzas patriotas de Venezuela y la Nueva Granada recuperan su capacidad de enfrentar la reconquista entramos en una etapa en la que el término «revolución», particularmente en cuanto designa el acontecimiento revolucionario en curso, tiene maneras nuevas de ser pensado, las cuales remiten a disputas importantes entre los líderes revolucionarios y al decantamiento de transformaciones sustanciales del orden político.

En primer lugar hay que tener en cuenta que cualquiera que sea la denominación que se utilice para aludir a la nueva forma de la comunidad política — «república», «gobierno popular representativo», «democracia», u otros- hay consenso en que la revolución ha significado el comienzo de una nueva forma de gobierno en todo el profundo sentido que la noción de régimen político tenía en la época13. Hay la conciencia de que la revolución ha significado un cambio fundamental en el ordenamiento social, pues llegan a pensar, como lo hace José Ignacio de Márquez en el congreso constituyente de Cúcuta en 1821, que «los vínculos sociales» han quedado rotos por «la revolución y separación de la metrópoli», lo cual plantea la exigencia de refundar el pacto social. Simultáneamente se hace

13 Véase, por ejemplo, las discusiones en el Congreso Constituyente de 1821(Cúcuta) (1971: 37-38; $40-41 ; 44-45 ; 57-62 ; 75-77 ; 91 ; 687 ; 714$ ). La importancia atribuida a la forma de gobierno puede entreverse en palabras como las de Jose María Salazar: «La forma de gobierno es la primera cuestión de entidad que se ofrece a un pueblo al emanciparse» (1914: 60). 
posible pensar que las desigualdades han quedado desnaturalizadas, aunque no ignoran que la desigualdad no ha sido suprimida. José María Salazar, por ejemplo, indica que la revolución ha nivelado las fortunas quitándole los cimientos a un régimen aristocrático, mientras que Bolívar le escribe a Santander: «Me parece una locura que en una revolución de libertad se pretenda mantener la esclavitud», y en una proclama alega: «tenemos la igualdad absoluta hasta en las costumbres domésticas» (Congreso de Cúcuta, 1971, Libro de Actas: 75; Salazar, 1914: 60; Hernández de Alba, 1988: 137; Bolívar, 1976: 72).

Las alusiones a revolución subrayan también la asociación con la independencia nacional, pues los hombres públicos tienden a creer que la revolución culminará cuando sean definitivamente expulsados los soldados españoles. En este sentido se hace corriente la denominación de «sistema colonial» o «régimen colonial» para referirse al periodo anterior a la revolución, periodo que, como en la década de 1810, es asociado a oscurantismo y arbitrariedad (Congreso de Cúcuta, 1971, Libro de Actas: 718; Salazar, 1914: 69)

En la medida que la independencia es convertida en un imperativo absoluto que todavía enfrenta enemigos externos poderosos, diversos líderes se preguntan si es posible conquistarla al mismo tiempo que la libertad. No pocos creen que fue el deseo simultáneo de la independencia y la libertad lo que llevó al descalabro a las primeras repúblicas, y que seguir queriendo ambas cosas en un momento en que permanece la amenaza militar española, puede dar al traste nuevamente con todos los esfuerzos emancipadores. Esa inquietud la mostraron varios diputados en el Congreso de Cúcuta, y el mismo vicepresidente Santander la expresó en 1820 cuando escribió:

«Un otro error ha sido muy común en nuestra revolución. Hemos confundido la libertad y la independencia. Queríamos ser independientes del gobierno español, y queríamos al mismo tiempo gozar de los derechos de los hombres libres, como si hubiéramos quedado ya independientes. No nos contentábamos con que los españoles no fuesen nuestros amos: queríamos que la libertad estuviese tan perfectamente establecida, como la veíamos en la América del Norte al cabo de muchos años. Este error hasta ahora ha venido a disiparse, pues vemos con satisfacción que los esfuerzos de todos los pueblos se dirigen a no depender de los españoles, y esperar al tiempo que les vaya dando posesión de su libertad».

Esta tensión entre independencia y libertad resulta fundamental durante este periodo: es la manifestación del deseo de modular el ritmo de la revolución, sobreponiendo la unidad patriótica a las disociadoras demandas de libertad. Pero no falta quien, como Antonio Nariño, recuerde a las autoridades que demandar el aplazamiento de la libertad choca con la naturaleza de un «gobierno libre» (Santander, 1988: 17-18)14.

${ }^{14}$ En 1823, Nariño increpó así a un contradictor: «iqué diablos entiende por federación, cuando hasta los toros del encierro le parecieron federados? Y, ipor qué es este espanto en una República libre y con una constitución que garantiza la libertad de la imprenta y de las opiniones? ¿Por qué
Tras una crítica como esa de haber confundido la libertad y la independencia se encuentra un juicio extremadamente severo respecto a la primera etapa de la revolución. La revolución arranca en 1810, hay consenso en esto, y hay también una inclinación generalizada a ver la primera etapa de la revolución con cierta conmiseración, pues la asocian a luchas fratricidas, desunión del Reino, exaltación de las pasiones, y, en síntesis, a federalismo. Bolívar, por ejemplo, insta en 1823 a Santander a hacer publicar un artículo en la Gaceta de Bogotá contrastando lo pasado y lo presente, la vieja y la nueva Colombia, y le insiste en que no involucre a «Nariño para nada ni a ninguna persona odiosa de las patrias viejas». Mientras que un sacerdote y congresista explica en 1824 en un sermón que la reconquista española y sus violencias se habían debido a que en la primera etapa de oposición a España, en lugar de las virtudes patrióticas habían brotado «pasiones de toda especie» que ese sacerdote no duda en calificar de «culpas que nosotros debíamos expiar» (Hernández de Alba, 1988: 64; de Talavera, 1824: 5).

La revolución es motivo sin embargo de otro tipo de reflexión: los relatos sistemáticos que no dudo en calificar de historiografía fundacional. Se trata de obras como la conocida Historia de la «revolución» de la República de Colombia de José Manuel Restrepo (1827) y el ignorado «Bosquejo político de la América antes española» de José María Salazar (1914). Trabajos que son parte de una estrategia diplomática de la joven nación pero que son simultáneamente una contribución al intento de fijar el curso de la revolución. En este sentido vale la pena reparar en dos vectores analíticos de esa historiografía fundacional propios de la época y olvidados por la historiografía del siglo XX. En primer lugar esos trabajos lograron dilucidar el tipo de vínculo que habían mantenido las sociedades americanas con España y de esta manera pudieron limitar analíticamente el carácter supuestamente inevitable de la revolución y de la separación. En segundo lugar esos trabajos pensaron de manera muy compleja la naturaleza del cambio operado con la revolución. Para Restrepo se trataba no solo de la independencia sino de una «transformación política» en la que el gobierno sufrió «una variación absoluta» respecto al tiempo del predominio español, operándose una «completa revolución» en las ideas del pueblo, el cual comenzó a ilustrarse y a participar en los asuntos públicos (Restrepo, 1827, t. I: $135,182) 15$.

Surgida en un tiempo en que se incuba una aguda confrontación entre los amigos de Bolívar y Santander, esta historiografía fundacional de mediados de la década de 1820 no está particularmente tocada por esas disputas «partidistas» que son mucho más que un lío de personalidades, y que tienen consecuencias decisivas sobre el relato de la revolución. Porque si en un primer momento - mientras

es más delito en el día la palabra federación que la de Fernando VII? ¿Dirá V. que esta palabra es destructora de la misma constitución? No, señor mío, las opiniones de Pedro, Juan, ni Diego, en un gobierno libre no destruyen las leyes, antes bien las fortifican» (Nariño, 1823).

El texto de Salazar, «Bosquejo político de la América antes española», apareció publicado en el Boletín de la Academia Nacional de la Historia [1913, t. II: n. ${ }^{\circ} 4$; 1914, t. III, n. ${ }^{0}$ 1] (1914: 43-77). Es posible que Salazar hubiera redactado este texto entre 1823 y 1827 durante su estadía en Estados Unidos, donde fue enviado como diplomático por el gobierno colombiano. 
había existido un enemigo externo visible - los líderes independentistas habían tenido una mirada más bien uniforme sobre el acontecimiento revolucionario, con la expulsión definitiva de los españoles se abre una etapa de disputas que se convierten en dos maneras bien diferenciadas de pensar la revolución. Dos maneras de entender la revolución que podemos cobijar con las designaciones de «enfoque boliviano»y «enfoque liberal»16.

Antes de bosquejar dichas interpretaciones boliviana y liberal de la revolución, vale la pena indicar que episodios como la rebelión de Páez en Venezuela en 1826 o el intento de asesinar a Bolívar dos años más tarde, actualizan la utilización del término revolución en su sentido de simple trastorno del orden. Sin embargo, estas designaciones que dan cuenta de la lucha entre los allegados a los dos líderes se abren sobre una conceptualización más general de la revolución. De hecho las diferencias de enfoque no impiden que unos y otros crean estar en una época de sacudimientos universales, que le permite escribir a Juan García del Río en 1829:

«Hemos asistido en nuestros días al drama de la revolución más atroz y más benéfica a un tiempo mismo de cuantas recuerdan los anales de los pueblos» (1972 [1829]: 29).

El mismo Juan García del Río es quizá el más refinado intérprete intelectual de la visión boliviana de la revolución. Según el cartagenero, en Colombia la revolución significó dar un énfasis democrático a las ideas hasta llegar a lo que él llama «el republicanismo más desenfrenado», en medio del cual se proclamó «la primera de las quimeras en lo físico y moral: la igualdad de los niveladores». Se trata de una perspectiva que enfatiza los «errores» de la revolución: la violencia y el desorden, y que enfatiza igualmente el rol de los militares y de la ciudad de Caracas en la revolución. Si la revolución está inficionada de aquel desenfreno republicano, se trata, por lo tanto, de atemperar la revolución, de darle un punto de anclaje. García del Río exhorta entonces a Bolívar de la siguiente manera:

«La América y la Europa aguardan que V. E. anuncie el fin de la revolución de Colombia, contribuyendo a que se desplieguen los socorros tutelares de un poder que contenga en el estado la fiebre democrática, que cierre las heridas de la patria, y presente de nuevo en el teatro del mundo a la nación colombiana, brillante, tranquila y majestuosa, por su crédito, sus instituciones y su poderío»(García del Río, 1972 [1829]: 36, 50)17.

${ }^{16}$ Estas designaciones no hubieran sido extrañas a los hombres de la época. En 1827 de manera reiterada Francisco Soto se define a sí mismo y define a sus amigos como «liberales». Usa también la expresión «bolivianistas» para referirse a sus contradictores. Ver Francisco Soto, «Memorias para la historia de la legislatura de Colombia en 1827» (1978: 127, 128, 130, 131, 132, 133, 134 135, 136, 144, 147, 148, 149, 150, 153, 155, 156, 158, 160, 161, 162, 174). A los «bolivianos tambièn aluden en «Retratos», EI Zurriago, 1828. «Liberal», sin embargo, no alude a una pertenencia partidista institucionalizada por entonces inexistente bajo esta etiqueta.

Un artículo afirmando la preeminencia de los militares: «Diálogo entre un Colombiano y un Europeo sale en El Amanuense, 1828; una recusación de quienes afirman que el impulso revolucionario provino de Caracas en «Torpe calumnia» se lee en La Bandera Tricolor, 1829.
La visión liberal de la revolución, por su parte, la encarna muy bien Vicente Azuero, quien escribe así en 1829 para indicar la gran ruptura operada con la revolución:

«En 19 años de revolución alimentados continuamente de ideas republicanas, ellas han hecho toda la base de nuestras esperanzas, han cambiado del todo nuestros sentimientos y han formado, por decirlo así, toda nuestra vida intelectual».

Si Azuero subraya que la revolución comienza en 1810 es porque desea recusar a quienes afirman que Bolívar es el origen de la libertad y de la nación, y que el impulso revolucionario provino de los militares caraqueños. Según Azuero desde 1810 se había tomado el camino irreversible de un «gobierno popular representativo» con el consiguiente repudio a la monarquía. La monarquía constitucional es por lo demás desdeñada por Azuero como «una eterna revolución», pues él piensa que la Corona, la nobleza y los comunes no pueden ser sino tres ejércitos y tres soberanos en conflicto (Azuero, 1831).

Es preciso reparar en el optimismo implícito en esta visión liberal, optimismo tanto en el sentido que la sociedad va a ser regenerada por el régimen democrático, como en el sentido que Colombia constituye un puesto de vanguardia de la revolución por la libertad. De manera que si García del Río insta a Bolívar a detener la revolución, los líderes afines a Santander tienden a pensar que la revolución debe proseguir.

Finalmente, deseo subrayar algo muy importante: en el siglo XIX quienes analizaron la revolución observaron con una lucidez hoy extraña a la historiografía el carácter doble de la revolución, esto es, haber tenido por consecuencia tanto la independencia como la democracia. Uno entre muchos que lo manifiestan así es José Eusebio Caro quien escribe en 1839 que «estas colonias, al independizarse adoptaron —o quisieron adoptar - las formas de gobierno democrático: no se contentaron con la independencia sino que ansiaron además por la libertad». El carácter democrático de la revolución lo ratifica por la misma época un periódico santanderista cuando dice:

«Proclamados desde nuestra emancipación política los principios de nivelación social entre todas las clases del estado, nuestras instituciones los han reconocido desde aquella época, y se ha efectuado en ellas una revolución democrática» (Caro, 1839; 1838).

\section{Referencias citadas}

\section{Fuentes primaria}

AGN, Fondo Justicia

«A los Enemigos de la Esclavitud», 1814 - Carta al reimpresor de la Bagatela num. 23». Archivo Histórico José Manuel Restrepo. 
Argos de la Nueva Granada, 1815a - n. ${ }^{\circ}$ 65, Santafé de Bogotá. Argos de la Nueva Granada, $1815 b$ - n. ${ }^{\circ}$ 73, Santafé de Bogotá. Argos de la Nueva Granada, $1815 \mathrm{c}-\mathbf{n} .^{\circ} \mathbf{7 9}$, Santafé de Bogotá. CMVJ: Casa Museo Veinte de Julio, Bogotá.

Década Miscelánea de Cartagena, 1814 - n. ${ }^{\circ} 1$.

Diario Político de Santafé de Bogota, 1810 - n. ${ }^{0} 1$.

El Alternativo del Redactor Americano, 1809 - n. ${ }^{\circ} \mathbf{2 8}$, Santafé de Bogotá

El Amanuense, 1828 - $\mathbf{n} .^{\circ}$ 43, 2 de marzo; Cartagena.

El Argos americano, $1811-\mathbf{n} .^{\circ}$ 32, Cartagena.

El Mensajero de Cartagena de Indias, $1814-\mathbf{n} .^{\circ} 33$.

El Republicano, 1815 - n. ${ }^{\circ} 31$, Tunja.

El Republicano, $1816-\mathbf{n} .^{\circ} \mathbf{3 6}$, Tunja.

El Zurriago, $1828-\mathbf{n}^{\circ}{ }^{\circ}$ 2, 27 de enero; Bogotá

Gaceta de Caracas, $1809 \mathrm{a}-\mathbf{n} .^{\circ} \mathbf{2 2}$.

Gaceta de Caracas, $1809 \mathrm{~b}-\mathbf{n} .^{0} \mathbf{3 4}$

Gazeta Ministerial de Cundinamarca, $1812-\mathbf{n} .^{\circ} 24$

Gazeta Ministerial de Cundinamarca, 1815: n. ${ }^{\circ} 12$

Gazeta Ministerial de la República de Antioquia, 1814a - n. ${ }^{\circ} 2$

Gazeta Ministerial de la República de Antioquia, 1814b - n. ${ }^{\circ} 14$.

Gazeta Ministerial de la República de Antioquia, 1815 - n. ${ }^{\circ} 24$.

La Aurora de Popayán, 1814 - n. ${ }^{\circ} 25$.

La Bagatela, $1811-\mathbf{n} .{ }^{\circ} \mathbf{2 1}$, Santafé de Bogotá.

La Bagatela, $1812-\mathbf{n} .^{\circ} \mathbf{2 9}$, Santafé de Bogotá.

La Bandera tricolor, $1829-\mathbf{n} .^{\circ}$ 2, 23 de julio; Bogotá.

La Constitución Feliz, 1810 - n. ${ }^{\circ}$ 1, Santafé de Bogotá.

Nariño, $1912-\mathbf{n} .^{\circ} 29$

Papel Periódico de Santafé de Bogotá, 1794a - n. ${ }^{\circ}$ 130, 21 de febrero Papel Periódico de Santafé de Bogotá, 1794b - n. ${ }^{\circ} 161,10$ de octubre.

Popayán, 1909a - n. ${ }^{0}$ XVIII.

Popayán, 1909b - n. ${ }^{\circ}$ XIX

Redactor Americano del Nuevo Reyno de Granada, 1808 - n. ${ }^{\circ}$ 46, Santafé de Bogotá Redactor Americano del Nuevo Reyno de Granada, 1809 - n. ${ }^{\circ}$ 56, Santafé de Bogotá.

Repertorio Colombiano, 1898, XVIII [2], Bogotá.

\section{Fuentes impresas}

ACEVEDO Y GOMEZ, J. de, 1808 - Relación de lo que executó el M. I. C. Justicia y Regimiento de la M. N. y M. L. Ciudad de Santafe de Bogota, Capital del Nuevo Reyno de Granada, para solemnizar el acto de la augusta proclamación que hizo dicha Ciudad, del Sr. D. Fernando VII, por Rey de España e Indias, el día 11 de Setiembre de 1808; Santafé de Bogotá.

AZUERO, V., 1831 - Paralelo entre el gobierno monárquico constitucional y el gobierno republicano puro, con relación a Colombia. Gaceta de Colombia, n.․ 544-554; Bogotá.
BOLÍVAR, S., 1976 - Doctrina del Libertador, 300 pp.; Caracas: Biblioteca Ayacucho. Manuel Pérez Vila ed.

CARO, J. E., 1838 - Prospecto. El labrador i artesano, n. ${ }^{\circ}$ 1; Bogotá, Septiembre 16.

CARO, J. E., 1839 - Sobre revolución. El Amigo del Pueblo, n. ${ }^{\circ}$ 24; Bogotá, Febrero 17.

CONGRESO DE CÚCUTA, 1971 [1821] - Libro de Actas; Bogotá: Banco de la República.

FERNÁNDEZ DE MADRID, J. L., 1809 - España salvada por la Junta Central. Ensayo poético que dedica al Exmo. Sr. D. Antonio de Narváez y la Torre, Mariscal de Campo de los Reales Ejércitos, Diputado por el Nuevo Reino de Granada, y Vocal en la misma Suprema Junta, con licencia en Cartagena de Indias.

FINESTRAD, J. de, 2000 - El vasallo instruido en el estado del Nuevo Reino de Granada y en sus respectivas obligaciones, 406 pp.; Bogotá: Universidad Nacional. Transcripción de M. González.

FRIEDE, J. (ed.), 1982 - Rebelión comunera de 1781; Bogotá: Instituto Colombiano de Cultura. Documentos, 2 vols

HERNÁNDEZ DE ALBA, G. (ed.), 1984 - Proceso de Nariño; Bogotá: Presidencia de la República. 2 tomos.

HERNÁNDEZ DE ALBA, G. (ed.), 1988 - Cartas Santander-Bolívar, vols. II, IV; Bogotá: Biblioteca de la Presidencia de la República.

GARCíA DEL RÍO, J., 1972 [1829] - Meditaciones colombianas, 377 pp.; Medellín: Editorial Bedout.

LEÓN, A. de, 1816 - Discurso político moral sobre la obediencia debida a los reyes, y males infinitos de la insurrección de los pueblos. Predicado en la Catedral de Santafé de Bogotá por el D. D. A. L., Prebendado de aquella Santa Iglesia, año de 1816. Santafé de Bogotá: Imprenta de D. Bruno Espinosa, por Nicomedes Lora.

LOSADA, J. I., 1815 - Voto del C. Dr. José Ignacio Losada sobre la expulsión de españoles europeos en la sesión, que el Serenísimo Colegio Electoral tuvo en Santafé el día 31 de Mayo de 1815; Santafé de Bogotá: Imprenta del Estado.

MENDOZA BUENO, M. de, 1814 - Copia adicionada de la representación hecha al Senado de Tunja, con motivo de los padecimientos del D. D. Mariano Bueno; Santafé de Bogotá: Imprenta del C. B. Espinosa.

NARIÑO, A., 1823 - Los toros de Fucha. Al autor de el patriota; Bogotá: Imprenta de Espinosa. Marzo 5.

ORTIZ, S. E. (ed.), 1965 - Escritos de dos economistas coloniales: Don Antonio de Narváez y La Torre y Don José Ignacio de Pombo, 273 pp.; Bogotá: Banco de la República.

RODRíGUEZ, M. del S. (ed.), 1978 - Papel Periódico de Santafé de Bogotá, 7 tomos; Bogotá: Banco de la República. Edición facsimilar.

POSADA, E. (ed.), 1989 - Congreso de las Provincias Unidas 1814-1816, t. 2, Biblioteca de la Presidencia de la República, Bogotá.

RESTREPO, J. M., 1827 - Historia de la revolución de la república de Colombia, t. 1; París: Librería Americana.

ROSILLO, A. M., 1805 - Sermón predicado en la Iglesia Catedral de la ciudad de Santafé de Bogotá el día 24 de febrero de 1805, en la solemnidad de acción de gracias que con asistencia del Excmo. Sr. Virrey, de todos los tribunales, y de los individuos de la Expedición de la Vacuna, y su Vicedirector don Joseph de Salvany, fue celebrada para Expe dicion de la Vacua y su Vicy diector don joseph manifestar el reconocimiento de este nuevo reyno a Dios, y al Rey por este beneficio Santafé de Bogotá: Imprenta de D. Bruno Espinosa de los Monteros.

SALAZAR, J. M., 1804 - El placer público de Santafé. Poema en que se celebra el arribo del Excelentísimo Señor Don Antonio Amar y Borbón, Caballero profeso del orden 
de Santiago, Teniente General de los Reales Exércitos, Virrey, Gobernador y Capitán Ceneral del Nuevo Reyno de Granada, y de la Excelentísima Señora su Esposa Doña Francisca Villanova y Marco; Santafé de Bogotá: Imprenta Real.

SALAZAR, J. M., 1914 - Obras inéditas del Dr. J. M. Salazar. Bosquejo político de la América antes española. Boletín de la Academia Nacional de la Historia, año III, tomo III, n. ${ }^{\circ}$ 1, marzo 31; Caracas.

SANTANDER, F. de P., 1988 - Escritos autobiográficos 1820-1840, 293 pp.; Bogotá: Biblioteca de la Presidencia de la República.

SOTO, F., 1978 - Mis padecimientos y mi conducta pública y otros documentos, 193 pp.; Bogotá: Academia Colombiana de Historia.

TALAVERA, M. de, 1824 - Oración pronunciada en la Iglesia Metropolitana de Bogotá por el Doctor Mariano de Talavera, miembro de la Cámara de Representantes de dicha República el 7 de agosto de 1824 aniversario de la victoria de Boyacá; Cartagena: Imprenta del Gobierno por Juan Antonio Calvo.

TERREROS Y PANDO, E., 1788 - Diccionario castellano con las voces de ciencias y artes y sus correspondientes en las tres lenguas francesa, latina e italiana, t. 3; Madrid: Imprenta de la viuda de Ibarra, hijos y compañía.

TORRES Y PEÑA, J. A. de, 1809 - Oración que en la solemne fiesta de acción de gracias a Dios Nuestro Señor por las señaladas victorias que por el patrocinio de María Santísima Nuestra Señora consiguieron las armas españolas contra los ejércitos del usurpador Napoleón Bonaparte, celebró el Cura de la Parroquia de Nuestra Señora de las Nieves de Santafé de Bogotá, Capital del Nuevo Reino de Granada, pronunció D. José Antonio de Torres y Peña...; Santafé de Bogotá: Imprenta Real de Santafé de Bogotá.

TORRES Y PEÑA, J. A. de, 1960 - Memorias sobre la revolución y sucesos de Santafé de Bogotá, en el trastorno de la Nueva Granada y Venezuela, 1814. In: Memorias del Presbítero José Antonio de Torres y Peña; Bogotá: Editorial Kelly.

VALENZUELA Y MOYA, N. de, 1817 - Oración gratulatoria y parenética, pronunciada el día 10 de Septiembre de 1816 en la Parroquial de la Ciudad de Neiva, ante el Consejo de Guerra del Ejército Expedicionario, y solemne concurso en acción de gracias por el feliz éxito de las Armas Reales en la reconquista del Nuevo Reino de Granada; Santafé de Bogotá: Imprenta del Superior Gobierno, por Nicomedes Lora.

\section{Fuentes secundarias}

GUTIÉRREZ R., J. \& MARTíNEZ G., A., 2008 - La visión del Nuevo Reino de Granada en las Cortes de Cádiz (1810-1813); Bogotá: Academia Colombiana de Historia, UIS.

HERNÁNDEZ DE ALBA, G. (ed.), 1960 - Proceso histórico del veinte de Julio de 1810, 295 pp.; Bogotá: Presidencia de la República.

MONSALVE, J. D., 1920 - Antonio de Villavicencio (el Protomártir) y la Revolución de Independencia, t. I; Bogotá: Academia de Historia.

POSADA, E. (ed.), 1914 - El 20 de Julio, 537 pp.; Bogotá: Biblioteca de Historia Nacional.

TACKETT, T., 1997 - Par la volonté du peuple. Comment les députés de 1789 sont devenus révolutionnaires, 365 pp.; París: Albin Michel.

VANEGAS, I., 2009 - La revolución: un delirio criminal. Nueva Granada 1780-1808. In: La sociedad monárquica en la América hispánica (M. Carillo \& I. Vanegas, eds.): $227-$ 278; Bogotá: Ediciones Plural. 